\title{
MEMBANGUN BRANDING LOGO WISATA SEJARAH SUMATERA BARAT
}

\author{
Muhammad Rio Akbar, Riki Iskandar, Abulwafa Muhammad \\ Universitas Putra Indonesia YPTK Padang \\ e- mail : rioakbar10@gmail.com,60rikiiskandar@gmail.com, abulwafa@upiyptk.ac.id
}

\begin{abstract}
Abstrak
Pemerintah Sumatera Barat Saat ini sedang mengembangkan diri sebagai salah satu destinasi wisata di dunia, terlebih saat Sumatera Barat berhasil memenangkan beberapa Item dalam kompetisi Destinasi Wisata Halal Dunia. Keunikan masyarakat, budaya, keindahan alam dan keragaman kuliner menjadi andalan pemerintah dalam memajukan sektor pariwisata. Sumatera Barat juga didukung oleh keragaman warisan budaya masa lalu / wisata sejarah, yang memiliki potensi besar untuk dikembangkan. Penelitian ini dilakukan untuk menganalisa kondisi branding promosi wisata sejarah Sumatera Barat yang telah ada saat ini, didukung dengan konsep branding Desain Komunikasi Visual. Penelitian ini diharapkan menemukan berbagaimacam hal yang dapat dijadikan referensi guna mendesain dan membangun branding logo romosi Wisata Sejarah suamtera Barat yang terintegrasi.
\end{abstract}

Kata Kunci : branding, wisata sejarah, logo, desain komunikasi visual

\section{PENDAHULUAN}

\section{Latar Belakang}

Pemerintah Sumatera Barat Saat ini sedang mengembangkan diri sebagai salah satu destinasi wisata berkelas dunia, terlebih saat Sumatera Barat berhasil memenangkan beberapa Item dalam kompetisi Destinasi Wisata Halal Dunia. Keunikan masyarakat, budaya, keindahan alam dan keragaman kuliner menjadi andalan pemerintah dalam memajukan sektor pariwisata. Sumatera Barat juga didukung oleh keragaman warisan budaya masa lalu / sejarah, yang memiliki potensi besar untuk dikembangkan sebagai wisata sejarah.Untuk mewujudkan hal tersebut banyak hal yang telah dilakukan baik oleh pemerintah provinsi, kabupaten/kota, pelaku industri pariwisata, hotel, biro perjalanan untuk memperkenalkan wisata sejarah yang ada di Sumatera Barat. Bahkan ada salah satu kota di Sumatera Barat yang mendeklarasikan dan fokus mengembangkan kotanya sebagai Kota wisata dengan objek andalannya adalah wisata sejarah / Heritage Town. Berbagai media digunakan untuk mendukung promosi, dan membranding Wisata sejarah tersebut, namun sampai saat ini branding yang dilakukan masih berjalan sendiri. Belum ada Integrasi branding wisata sejarah yang dilakukan saat ini di Provinsi Sumatera Barat.Sehingga para wisatawan hanya fokus mengunjungi wisata sejarah yang telah lama dikembangkan, namun untuk destinasi wisata sejarah yang baru dikembangkan masih sedikit yang mengunjungi. Hal ini tentu menjadi perhatian untuk semua kalangan sehingga destinasi wisata sejarah yang lama maupun yang baru dikembangkan diserbu oleh wisatawan, sehingga memberikan dampak ekonomi yang saling berkaitan. Penelitian ini dilakukan untuk menganalisa kondisi branding promosi wisata sejarah Sumatera Barat yang telah ada saat ini, didukung dengan konsep branding Desain Komunikasi Visual. Penelitian ini diharapkan menemukan berbagai macam hal yang dapat dijadikan referensi guna mendesain dan membangun branding logo promosi Wisata Sejarah suamtera Barat yang terintegrasi.

\section{Tujuan Penelitian}

Penelitian ini dilakukan denga tujuan :

1. Melakukan analisa branding wisata sejarah yang ada saat ini di Provinsi Sumatera Barat.

2. Melakukan analisa alternative branding wisatasejarah secara di Provinsi Sumatera Barat.

3. Melakukan pembangunan branding logo wisata sejarah di Provinsi Sumatera Barat.

\section{Manfaat Penelitian}

1. Mengetahui bentuk branding wisata sejarah di Provinsi Sumatera Barat.

2. Mengetahui alternative pengmebangan branding wisata sejarah di Provinsi Sumatera Barat.

3. Menghasilkan branding logo wisata sejarah provinsi suamtera Barat.

\section{Batasan Masalah}

1. Hanya melakukan survey branding wisata sejarah saat ini hanya di 4 Kab. Kota yang ada, yaitu Kota Padang, Kota Sawahlunto, Kab. Tanah Datar, Kabupaten/ Kota Solok. 
2. Membangun branding logo wisata sejarah provinsi Sumatera Barat.

\section{METODOLOGI PENELITIAN}

1. Mulai

Tahapan dimana awal kegiatan penelitian dilakukan.

2. Survey Lapangan

Survey Lapangan dilakukan untuk melihat lebih dekat dan untuk mengetahui permasaalahaan sebenarnya yang terjadi.

3. Identifikasi Masalah

Dari hasil penelaahan sumber pustaka maka permasalahan yang dapat dirumuskan adalah melakukan analisa branding promosi wisata sejarah Sumatera Barat

4. Menentukan tujuan

Dalam sebuah penelitian, tujuan merupakan hal yang paling menentukan terhadap apa yang akan dicapai nantinya. Dengan analisa-analisa terhadap permasalahan yang ada, maka dapat ditentukan tujuan dari penelitian ini yang merupakan hasil akhir dari pemecahan masalah.

5. Mempelajari Literatur

Untuk memaksimalkan hasil penelitian ini maka dilakukan kajian literatur yang berkaitan dengan Branding, Promosi, Wisata Sejarah Sumatera Barat. Literatur yang dipelajari diambil dari Jurnal, buku-buku, artikel internet dan kontak dengna pihak yang terkait.

6. Pengumpulan Data

Setelah permasalahan dirumuskan, dilakukan pengumpulan data pemasaran dan pelayanan konsumen yang terdiri dari penelitian lapangan (field research), penelitian perpustakaan (library research) dan penelitian laboratorium (laboratory research).

a. Penelitian Lapangan (field research)

Dalam penelitian lapangan ini merupakan observasi langsung ke tempat wisata sejarah Sumatera Barat.

b. Penelitian Perpustakaan (library research)

Untuk melengkapi konsep dan teori tentang branding, promosi, wisata sejarah, maka dilakukan penelitian perpustakaan dengan cara mencari referensi pendukung melalui buku-buku, jurnal-jurnal, e-book, blog, Media social, artikel, video, foto. Data yang akan dianalisis dalam penelitian ini yaitu mengambil data branding promosi wisata sejarah Sumatera Barat.

c. Penelitian Laboratorium (laboratory research)

Untuk melakukan pengujian terhadap penerapan sistem pendukung pengambilan keputusan, maka dilakukanlah penelitian laboratorium.

7. Analisa SWOT branding logo promosi wisata sejarah Sumatera Barat

Data-data yang sudah dikumpulkan akan dianalisa, agar dalam penentuan pola masukan dan keluaran akan lebih jelas Perancangan brading promosi wisata sejarah yang terintegrasi.

8. Perancangan Branding

Pada tahap perancangan desian branding yang perlu diperhatikan disini adalah penentuan desain yang tepat untuk diterapkan pada branding logo promosi wisata sejarah terintegrasi Sumatera Barat.

9. Pembangunan branding promosi wisata

10. Pengujian karya branding/ pameran

Pemaparan karya branding logo promosi wisata sejarah sumatera barat

11. Penarikan Kesimpulan

Pada akhir pembahasan dilakukan penarikan simpulan sebagai jawaban dari permasalahan bagaimana membangun branding promosi wisata sejarah Sumatera Barat.

\section{ANALISA DAN HASIL}

Destinasi wisata merupakan daya tarik bagi kedatangan wisatawan, baik dari dalam maupun luar negeri. Destinasi wisata dapat membantu ekonomi dan kehidupan masyarakat disekitaran destinasi wisata. Provinsi Sumatera Barat mempunyai destinasi wisata yang banyak sekali. Mulai dari yang modern hingga tempat-tempat 
yang mempunyai sejarah yang panjang. Destinasi wisata yang berada di Suamtera Barat banyak mengandung sejarah yang panjang mulai dari zaman kuno hingga penjajahan bahkan terdapat beberapa renovasi untuk memodernasikan tempat wisata tersebut. Destinasi wisata yang berada di Bukittingi seperti Jam Gadang, Lobang Jepang dan Fort de Kock. Dipilihnya destinasi wisata ini dikarenakan destinasi wisata disini sarat akan sejarah tentang penjajahan di kota Bukittingi.

Destinasi wisata yang berada di Sawahlunto seperti Lubang Kalam Sawahlunto dan Stasiun Kereta Api Sawahlunto serta Museum Goedang Ransoem. Dipilihnya destinasi wisata ini sebagai pembahasan saya dikarenakan destinasi ini merupakan destinasi yang terkenal dari Kota Sawahlunto. Destinasi Wisata yang berada di Tanah datar seperti Batu Angkek-angkek dan Istano Rajo Basa Pagaruyung. Dipilihnya destinasi wisata ini sebagai pembahasan saya dalam penelitian ini dikarenakan destinasi ini merupakan destinasi yang terkenal di Tanah Datar.

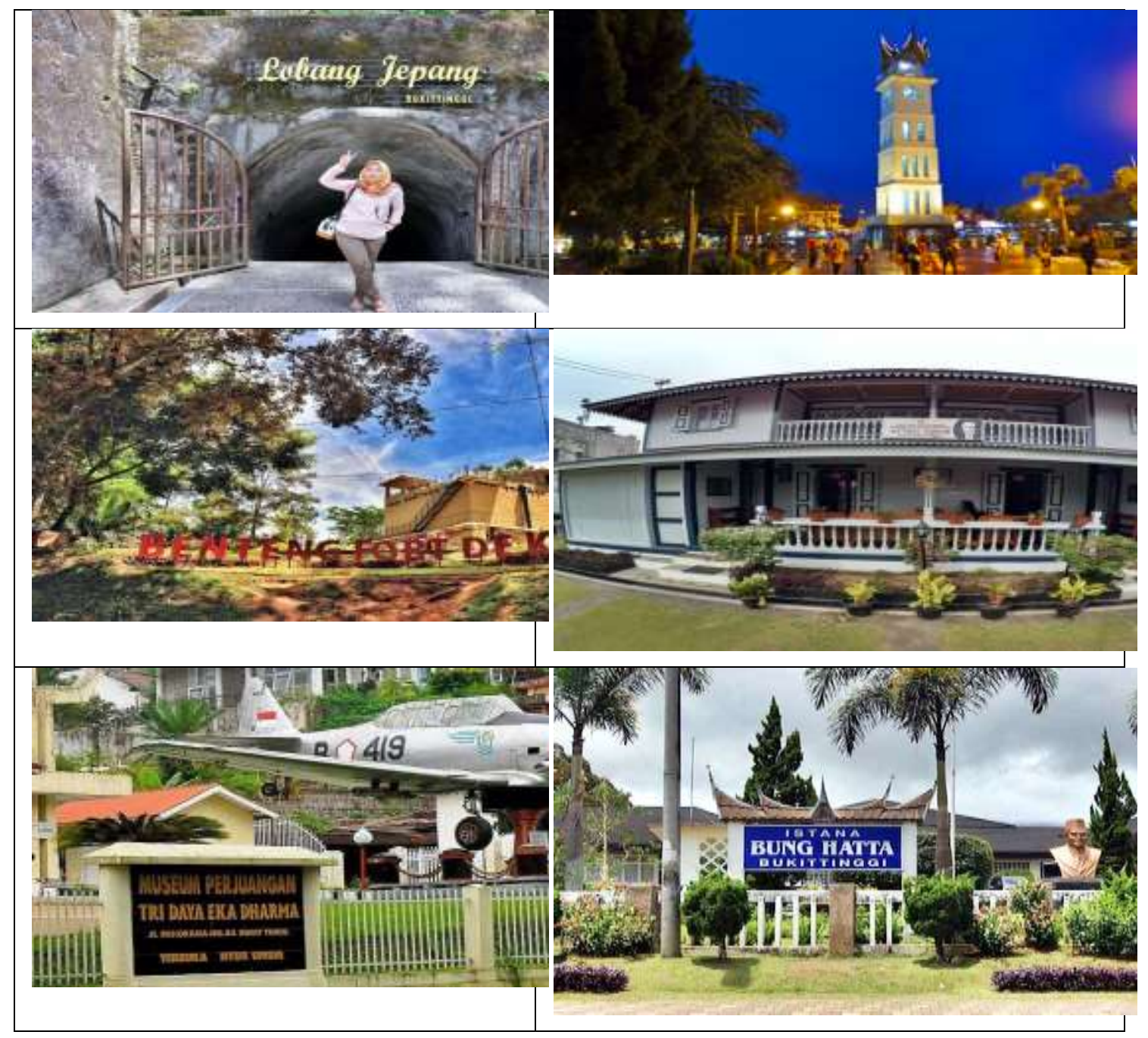




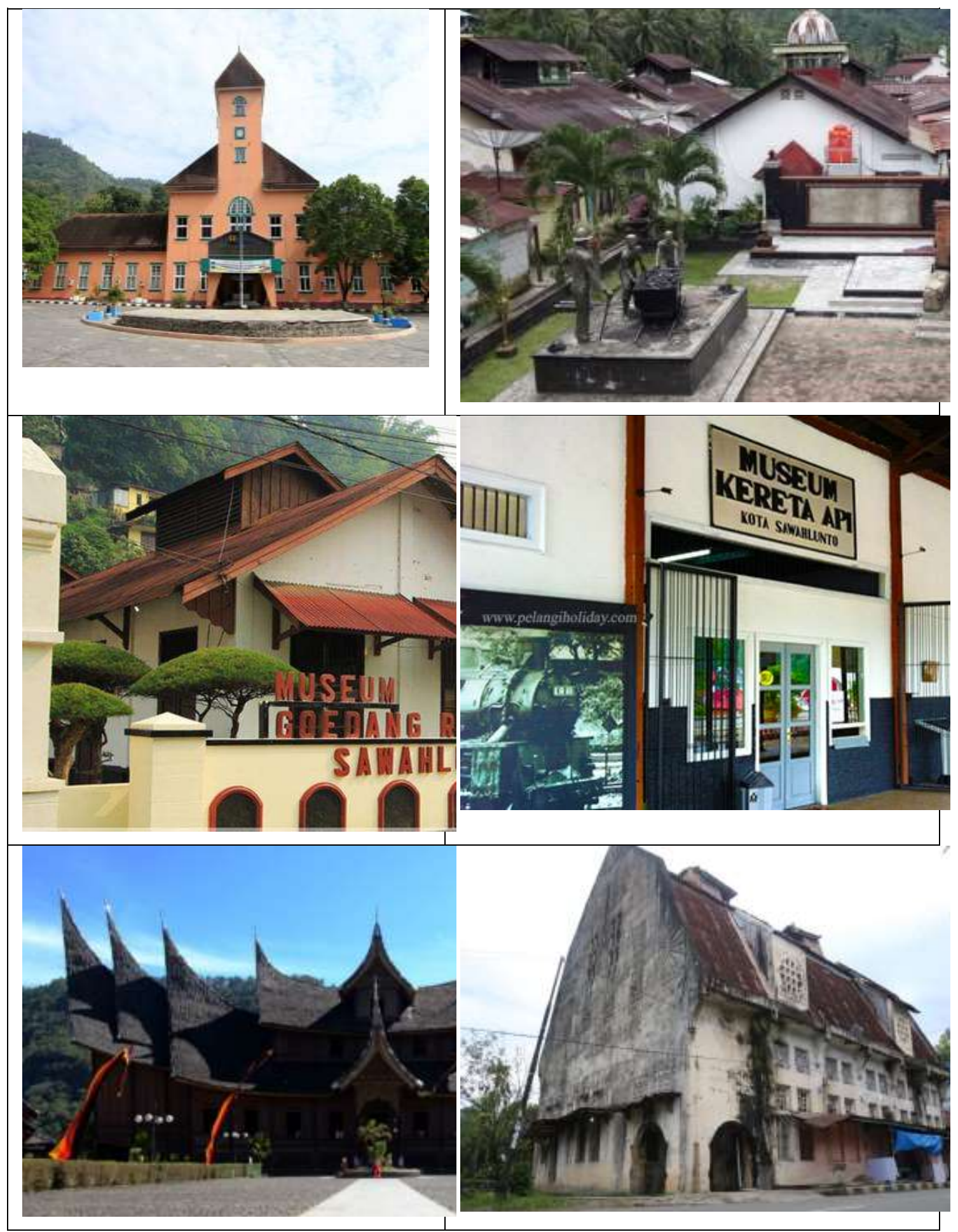




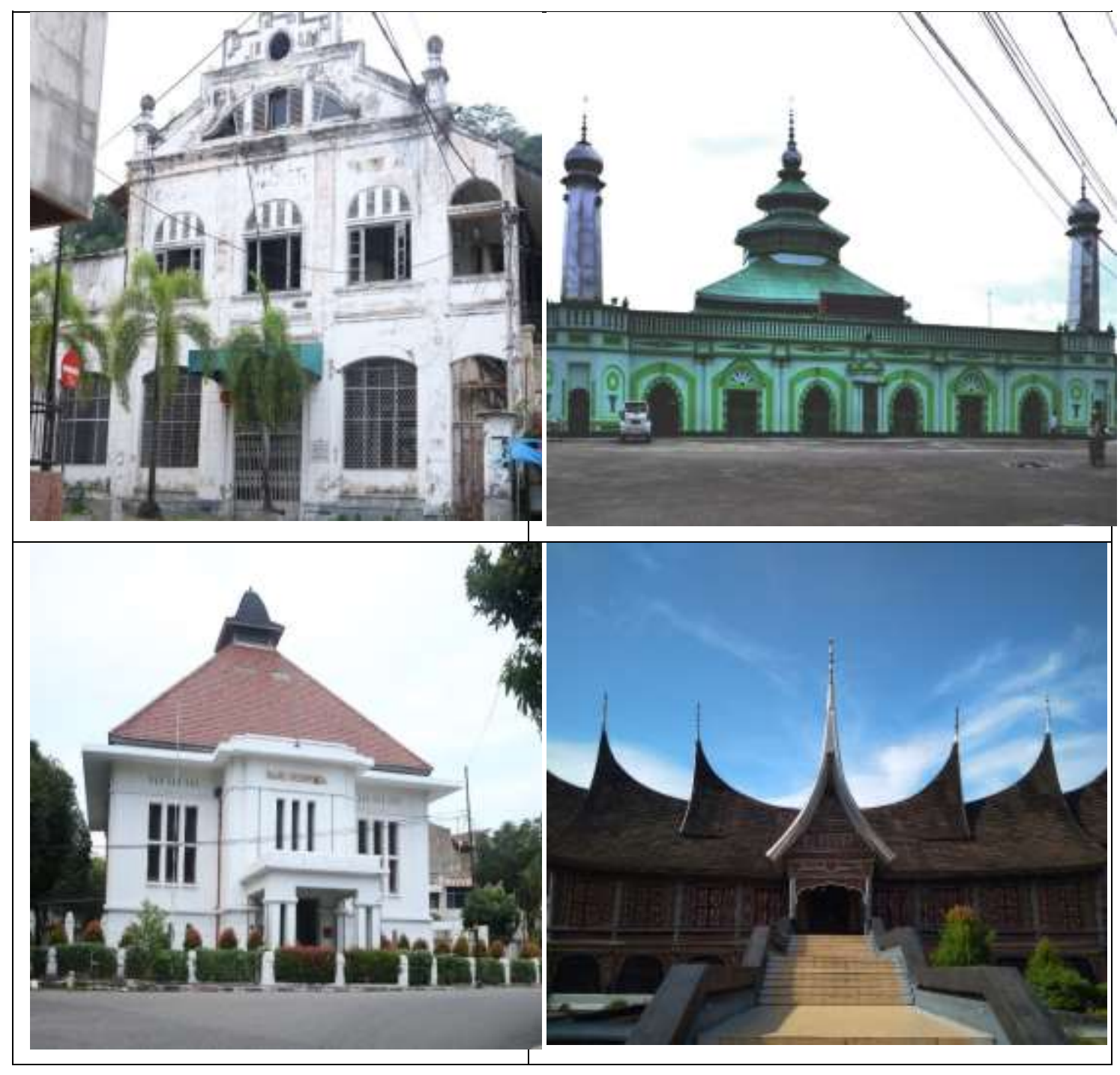

Dari Analisa masalah di lapang dan sesuai dengan tujuan penelitian maka dibangunlah branding wisata sejarah Sumatera Barat, Namun untuk saat ini peneliti hanya melakukan pengambilan data di Kota Padang, Kota Sawahlunto, Kota/Kab Solok, Kab Tanah Datar, Hal ini dilakukan karena daerah tersebut saat ini masing masing daerah mengembangan potensi pariwisata sejarahnya. Hasil dari analisa penelitian ini menghasilkan desain alternatif logo wisata sejarah Sumatera Barat. Dari beberapa alternative logo ini akan dililih mana alternative yang terbaik, tentu pemilihan ini nantinya berdasarkan pertimbangan tertentu. Selain itu peneliti juga akan mencoba mengembangkan alternatif logo lain, sebagai bahan pertimbangan dalam menentukan logo yang pas. 


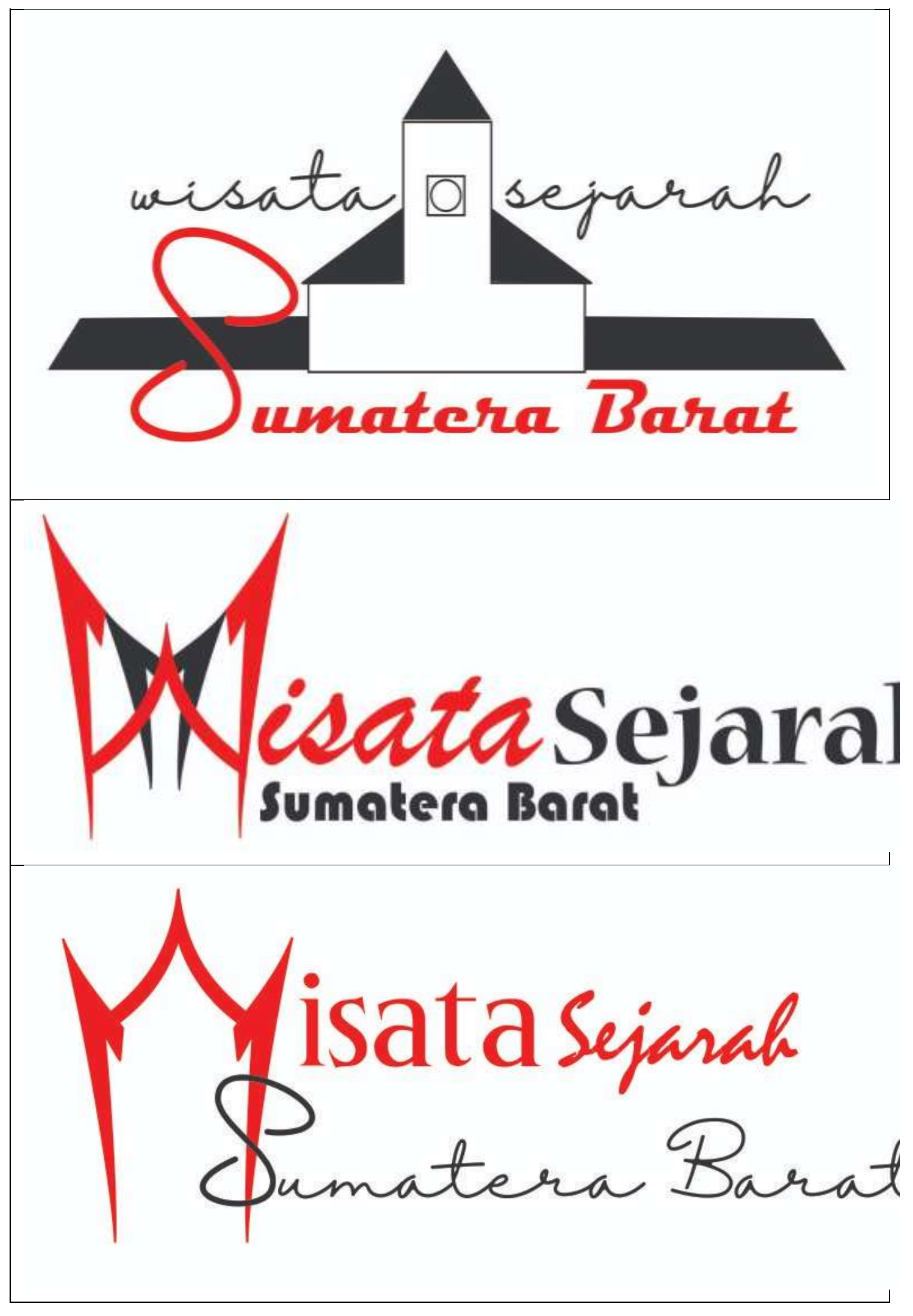



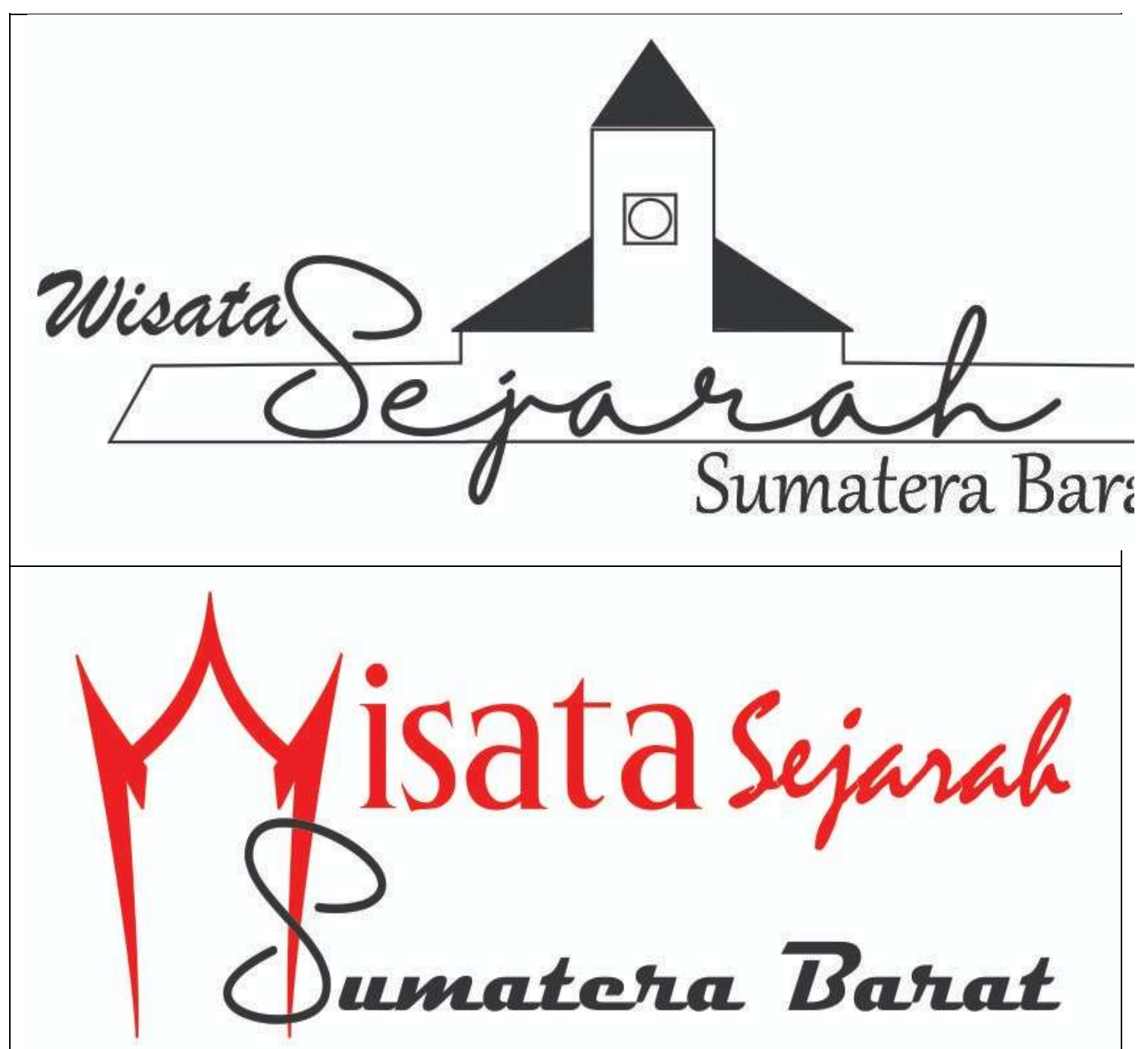
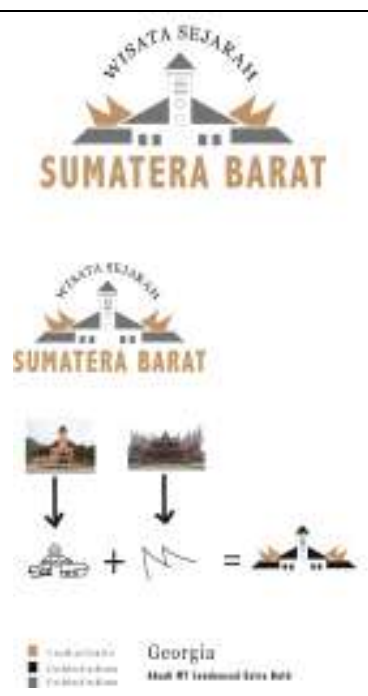

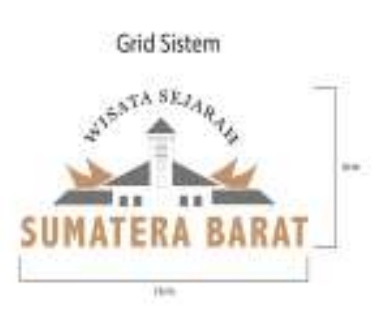

Black/White

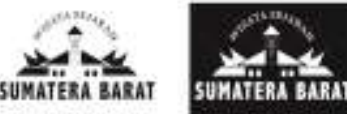

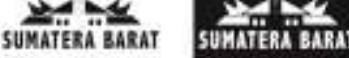

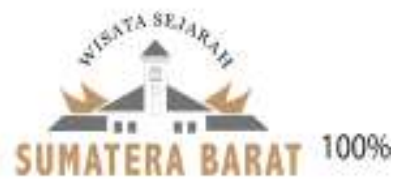

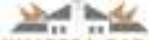

SUMATERA ВARAT $75 \%$

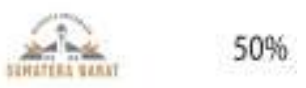

$25 \%$ 

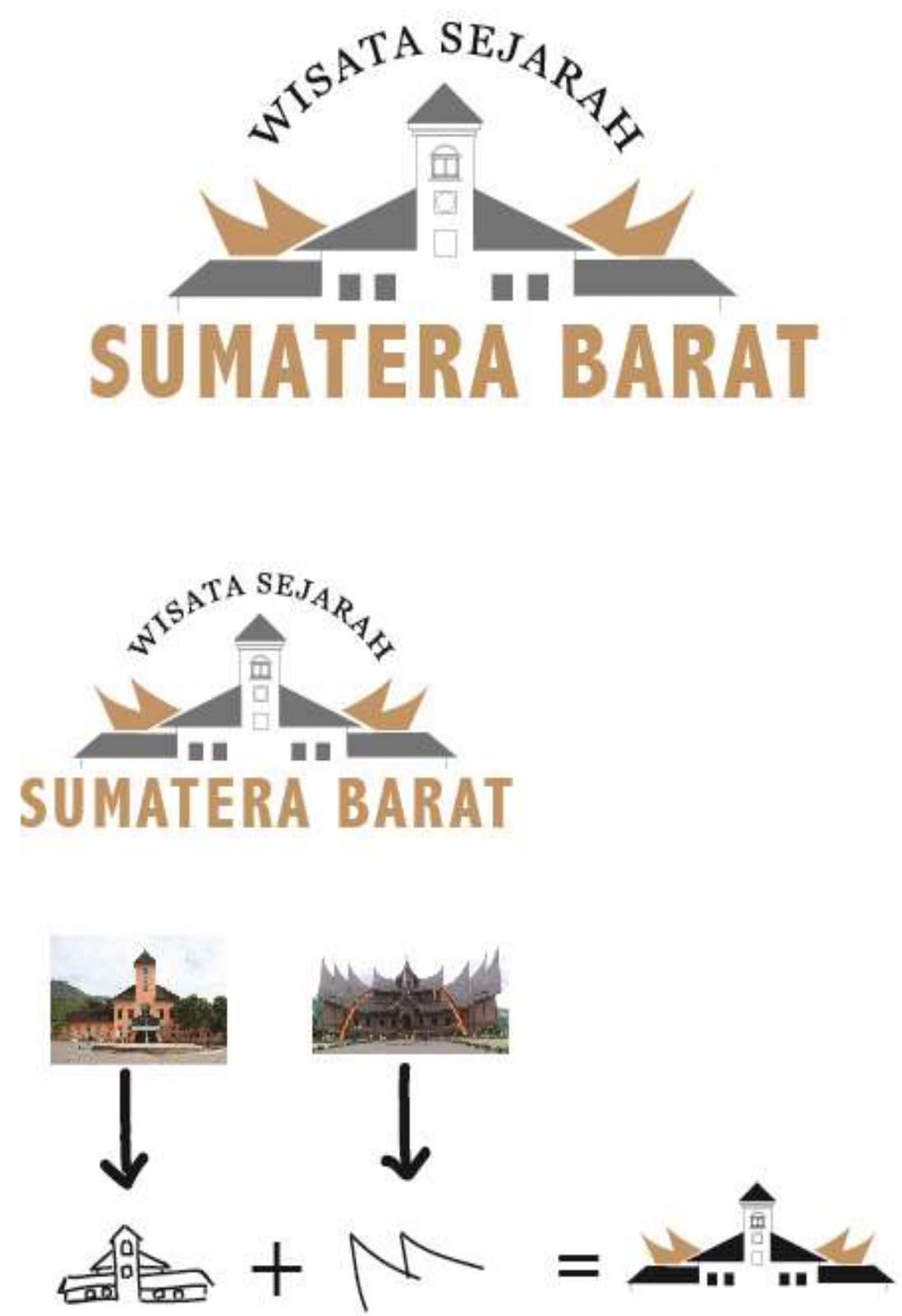

$\mathrm{C}: 25, \mathrm{M}: 40, \mathrm{Y}: 65, \mathrm{~K}: 0$

C:0,M:0,Y:0,K:100

C: $0, M: 0, Y: 0, K: 100$

Georgia

Abadi MT Condensed Extra Bold 


\section{Grid Sistem}

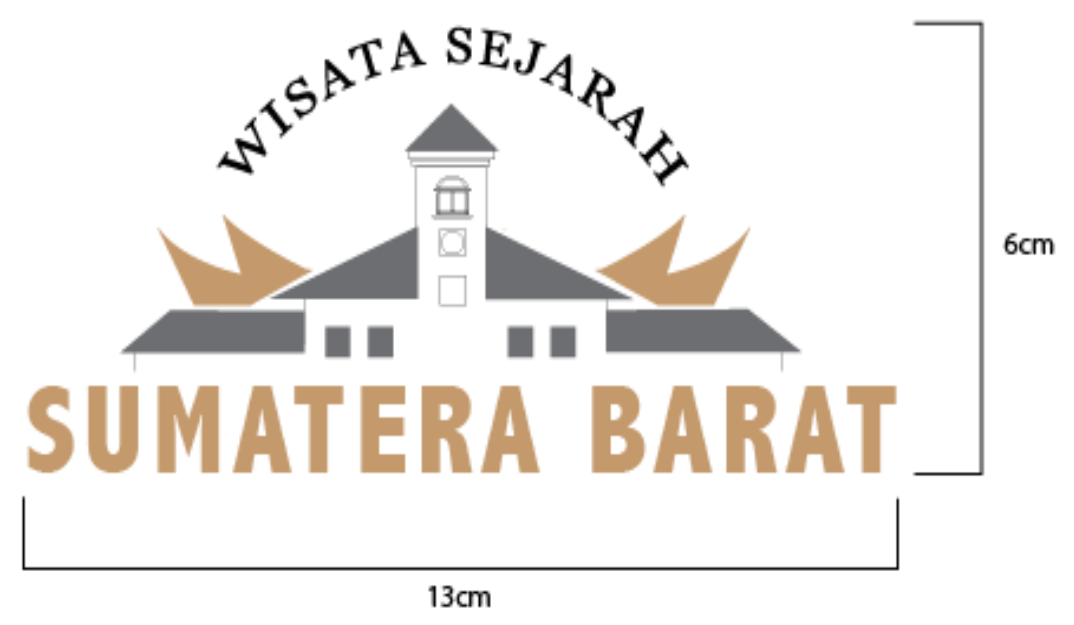

\section{Black / White}

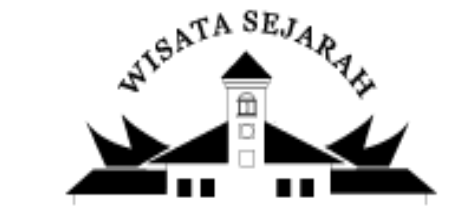

SUMATERA BARAT

(black)

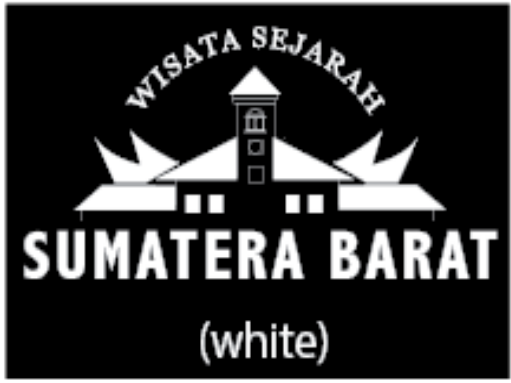




\section{SKALA}
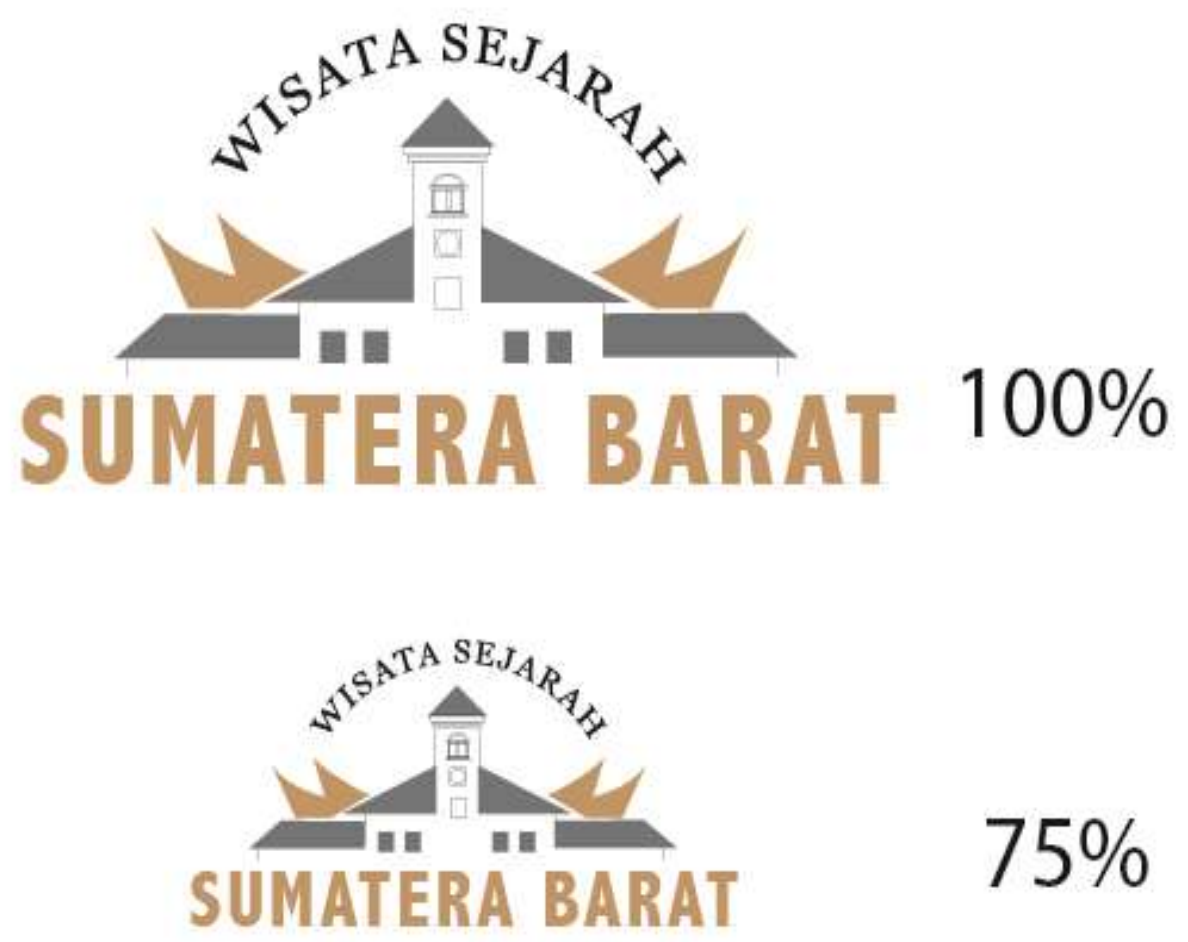

$75 \%$

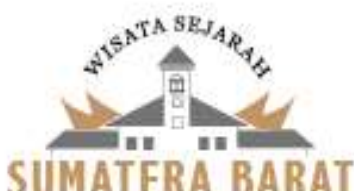

$50 \%$

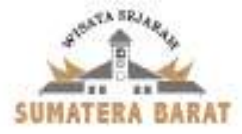

$25 \%$ 


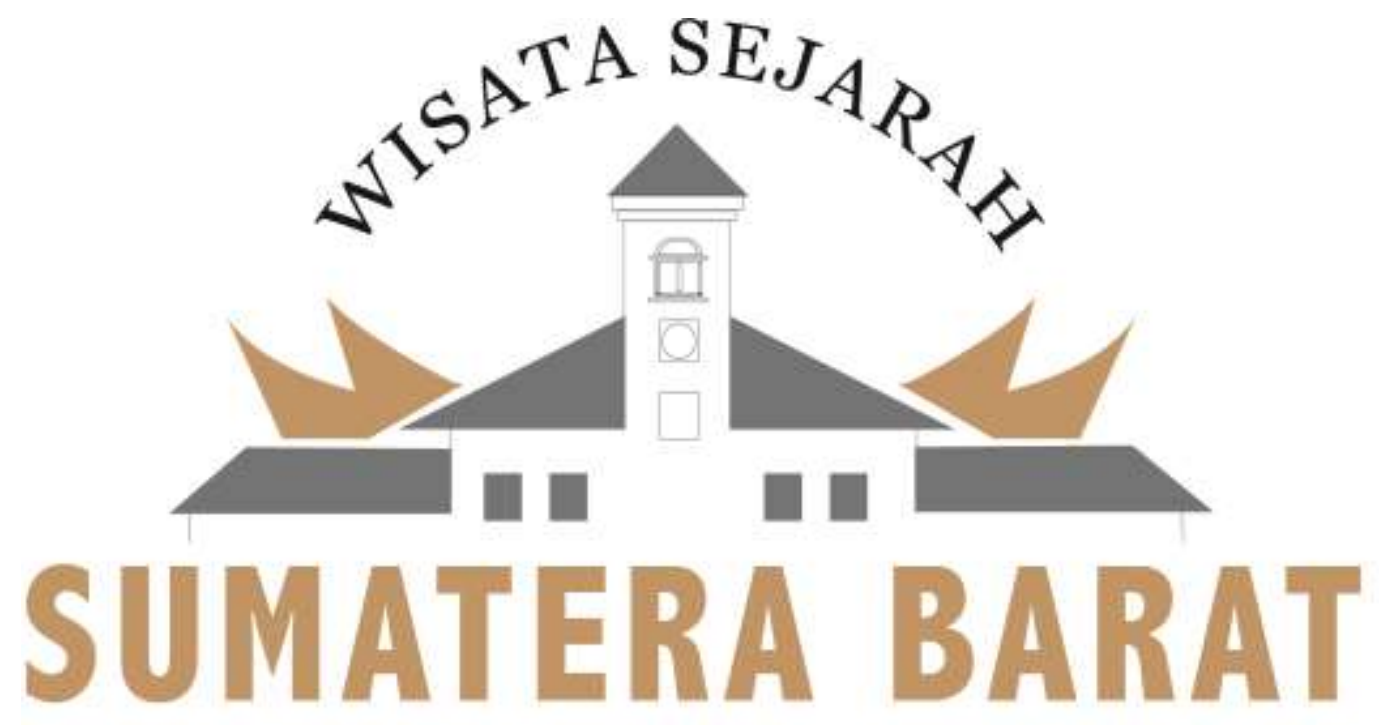

Gambar : Logo Branding Wisata Sejarah Sumatera Barat Terpilih

\section{KESIMPULAN DAN SARAN}

\section{Simpulan}

Penelitian ini menghasilkan sebuah logo branding wisata sejarah Provinsi Sumatera Barat.

\section{Saran}

Agar Hasil Penelitian ini perlu dikembangakn untuk wisata daerah di Kabupaten dan Kota lainya di Sumatera Barat, sehingga memiliki kekayaan referensi dan nilai budaya dan seajrah.

\section{UCAPAN TERIMAKASIH}

Kami mengucapkan Terimakasih kepada RISTEKDIKTI yang telah mendanai peneltian ini sehingga kami mengahsilkan luaran penelitian ini.

\section{DAFTAR PUSTAKA}

1. Aaker, David. 2014. Aaker On Branding. Jakarta : Gramedia.

2. Afrillita T, Nur. 2013. Analisis SWOT Dalam menentukan Strategi Pemasaran Sepeda Motor Pada PT. Samekarindo Indah di Samarinda. Jurnal. Universitas Mulawarman. Samarinda 2. Buchari, Alma, 2000, Manajemen Pemasaran dan Pemasaran Jasa, Cetakan Kelima, Bandung : Alfabeta Dharmesta, Basu Swastha, 2002, Azas-azas Marketing, Yogyakarta : Liberty

3. Cenadi, Christine S. Elemen-elemen dalam Desain Komunikasi Visual. Jurnal Nirmana volume 1 nomor 1, Universitas Kristen Petra, Surabaya, 1999. Cotton, Bob. The New Guide to Graphic Design. Phaidon, Oxford, 1990.

4. Hamidi, Kambiz dan Delbahari, Vahideh. 2011. Formulating a Strategy for a University Using SWOT Technique: a Case Study. Jurnal. HBIAU. Hamedan 
5. Hisrich, Robert D. \& Michael P. Peters. Marketting Decisions for New and Mature Products. Macmillan Publishing Co., New York, 1991.

6. Knapp, Duane. 2006. The Brand Mindset. Yogyakarta: Andi

7. Kusrianto, Adi. 2006. Pengantar Desain Komunikasi Visual. Yogyakarta: Andi.

8. Kotler, Philip dan Gary Amstrong. 1998. Marketing: An Introduction, 3rd Edition. New Jersey: Prentice-Hall Inc.

9. Kertajaya, Hermawan. Marketting Plus 2000 Siasat Memenangkan Persainagn Global. PT. Gramedia Pustaka Utama, Jakarta, 1996.

10. Muhammad Rauf Hidayat, Thamrin, Analisis Proses City Branding' Taste Of Padang' sebagai Brand Destinasi Pariwisata Sumatera Barat, Jurnal Kajian Manajemen dan Wirausaha Volume 01 Nomor 012019 ISSN: Online 2655-6499.

11. Rustan, Suryanto. 2013. Mendesain Logo. Jakarta : Gramedia 12. Saladin, Djaslim, 2006, Manajemen Pemasaran, Edisi Keempat, Bandung : Linda Karya 13. Sarwono, Jonathan, dan Lubis, Hary. 2007 Metode Riset untuk Desain Komunikasi Visual. Yogyakarta. Penerbit Andi. 14. https://gpswisataindonesia.wordpress.com/2014/05/07/wisata-sejarah-disumatera-barat/

12. Gusman, A. P. (2018, December). Penerapan Fuzzy Time Series Dalam Menganalisa Peramalan Kedatangan Wisatawan Setelah Diterapkan Konsep Halal Tourism Sumatera Barat. In Seminar Nasional Teknologi Informasi Komunikasi dan Industri (pp. 749-754). 